8. F. Bilotti, A. Alu, and L. Vegni, Design of miniaturized patch antennas with $\mu$-negative loading, IEEE Trans Antennas Propag 56 (2008).

9. S.K. Patel and Y.P. Kosta, Size reduction in microstrip based meandered radiating structure using artificial substrate, Int J Appl Electromagn Mech 41 (2013), 207-216.

10. Y. Zhang, W. Hong, C. Yu, Z. -Qi. Kuai, Y. -Dan. Don, and J. -Yi. Zhou, Planar ultrawideband antennas with multiple notched bands based on etched slots on the patch and/or split ring resonators on the feed line, IEEE Trans Antennas Propag 56 (2008), 3063-3068.

11. H. Attia, L. Yousefi, M.M. Bait-Suwailam, M.S. Boybay, and O.M. Ramahi, Enhanced-gain microstrip antenna using engineered magnetic superstrates, IEEE Antennas Wireless Propag Lett 8 (2009), 1198-1201.

12. M.M. Bait-Suwailam, O.F. Siddiqui, and O.M. Ramahi, Mutual coupling reduction between microstrip patch antennas using slottedcomplementary split-ring resonators, IEEE Antennas Wireless Propag Lett 9 (2010), 876-878.

13. O. Quevedo-Teruel, M.N.M. Kehn, and E. Rajo-Iglesias, Dual-band patch antennas based on short-circuited split ring resonators, IEEE Trans Antennas Propag 59 (2011), 2758-2765.

14. A. Habashi, J. Nourinia, and C. Ghobadi, Mutual coupling reduction between very closely spaced patch antennas using low-profile folded split-ring resonators (FSRRs), IEEE Antennas Wireless Propag Lett 10 (2011), 862-865.

15. S.K. Patel and Y.P. Kosta, Investigation on radiation improvement of corner truncated triband square microstrip patch antenna with double negative material, J Electromagn Waves Appl 27 (2013), 819-833.

16. S.K. Patel and Y.P. Kosta, Triband microstrip based radiating structure design using split ring resonator and complementary split ring resonator, Microwave Opt Technol Lett, in press.

17. J.D. Jackson, Classical electrodynamics, 3rd ed., Wiley, New York, NY, 1998.

(C) 2014 Wiley Periodicals, Inc.

\section{TOLPA FOR MM-WAVE: A WIDEBAND LOW PROFILE, OMNIDIRECTIONAL VER- TICALLY POLARIZED ANTENNA}

\section{Jean-Francois Zürcher}

Ecole Polytechnique Fédérale de Lausanne (EPFL), Laboratoire d'Electromagnétisme et d'Acoustique (LEMA), Bâtiment ELB, Station 11, CH-1015 Lausanne, Switzerland; Corresponding author: JF.Zurcher@epfl.ch

Received 7 May 2013

ABSTRACT: In an article (Zürcher, Microwave Opt Technol Lett 55 (2013), 516-521) published in 2013, a new antenna called tripod omnidirectional low profile Antenna has been presented. It is vertically polarized and has a radiation pattern similar to the classical monopole on a ground plane, with numerous potential applications for mobile communications, UWB, and others. The present article describes a scaled version of this antenna designed to work at mm-wave frequencies. (C) 2014 Wiley Periodicals, Inc. Microwave Opt Technol Lett 56:310 313,2014 ; View this article online at wileyonlinelibrary.com. DOI 10.1002/mop. 28071

Key words: low profile antennas; mm-wave antennas; omnidirectional antennas; wideband antennas

\section{INTRODUCTION}

The most frequently used antennas are probably those with vertical polarization and omnidirectional radiation patterns. Surprisingly, few of these antennas have been described in the literature within the mm-wave band. This reason and a dose of

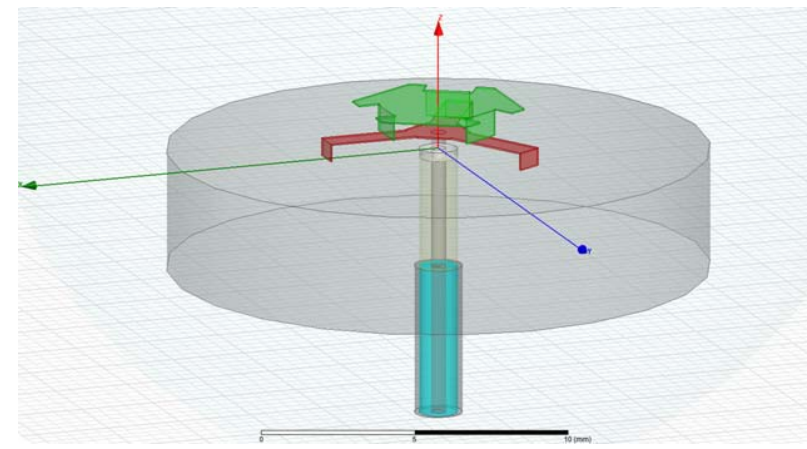

Figure $1 \mathrm{~mm}$-wave TOLPA HFSS model with a $4 \mathrm{~mm}$ thick ground plane and simplified $1.85 \mathrm{~mm}$ connector model. [Color figure can be viewed in the online issue, which is available at wileyonlinelibrary.com]

curiosity have motivated the transposition of the tripod omnidirectional low profile antenna (TOLPA) concept to the mm-wave band by means of a simple 1:4 dimensional scaling. The resulting mm-wave TOLPA covers roughly the $15-42 \mathrm{GHz}$ band. As the original microwave version of TOLPA was already quite small, the fabrication of a down-scaled version poses a considerable technological challenge. This point will be covered next.

\section{ANTENNA DESCRIPTION}

As for the original TOLPA, all simulations have been done with ANSYS HFSS v. 13.0.1 [1]. Bandwidth (BW) in this article is the relative BW (in \%) for which $\mathrm{S}_{11} \leq-10 \mathrm{~dB}$.

The layout of Ref. 2 was scaled in all dimensions (including the material thickness) by a factor of 4 . The original SMA connector with a $1.3 \mathrm{~mm}$ diameter pin had to be replaced with a $1.85 \mathrm{~mm}$ connector having a $0.5 \mathrm{~mm}$ diameter pin, which was available at the time of prototyping. Therefore, the TOLPA excitation had to be completely redesigned and the fact that the $1.85 \mathrm{~mm}$ connector had to be fastened with $4 \mathrm{M} 2.5$ screws necessitates a thick ground plane $(4 \mathrm{~mm})$. Furthermore, a tiny Teflon washer had to be added at the upper end of the ground plane drill to support and center the connector pin; this washer also plays a role in the matching of the antenna. All these structural details have been taken into account in the HFSS model shown in Figure 1

After some manual tuning of the antenna performance, the final dimensions of the antenna prototype are summarized next (refer to Ref. [2] for a description of the parameter signification):

$\mathrm{C} 1=1.075 \mathrm{~mm}$
$\mathrm{C} 2=2.875 \mathrm{~mm}$
$\mathrm{H} 1=0.55 \mathrm{~mm}$
$\mathrm{H} 2=0.825 \mathrm{~mm}$
$\mathrm{~L} 1=2.95 \mathrm{~mm}$
$\mathrm{~L} 2=0.7 \mathrm{~mm}$
$\mathrm{~W} 1=0.45 \mathrm{~mm}$
$\mathrm{~W} 2=0.725 \mathrm{~mm}$
th1 $=$ th2 $=50$ microns (Beryllium copper sheet thickness)

ground plane (GP) radius: $9 \mathrm{~mm}$

The total height of the radiating structure is $1.475 \mathrm{~mm}$ (without ground plane).

\section{ANTENNA FABRICATION}

The prototype manufacturing is based on the following techniques: 


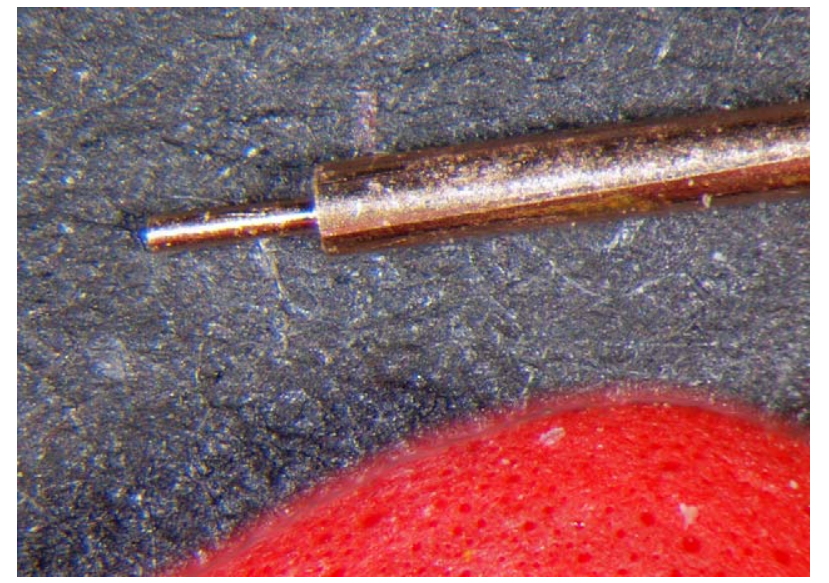

Figure 2 The $0.5 \mathrm{~mm}$ diameter pin extension with $0.2 \mathrm{~mm}$ end diameter. [Color figure can be viewed in the online issue, which is available at wileyonlinelibrary.com]

- Dual-side chemical etching of the Beryllium copper sheets that form the antenna structure.

- Ground plane: machined from brass on a lathe, then cleaned within ultrasonic bath.

- $1.85 \mathrm{~mm}$ connector pin extension: manufactured out of 0.5 $\mathrm{mm}$ diameter phosphorus bronze rib, and soldered to the center conductor of the connector.

- Teflon washer: machined on a lathe under optical magnification

Figure 2 shows a detail view of the pin extension together with part of a match tip (for scale indication)

Figure 3 shows the assembled GP, the $1.85 \mathrm{~mm}$ connector with its pin extension and centering Teflon washer.

Figure 4 shows the two antenna parts made of Beryllium copper after etching and bending along etched groves:

The soldering of the various parts of the antenna is not feasible due to the extremely small dimensions and, especially, due to the large thermal mass of the GP. Two-component highly conductive silver epoxy (Epo-Tek H-20E) has been used instead. Figure 5 shows the mm-wave TOLPA with its first antenna

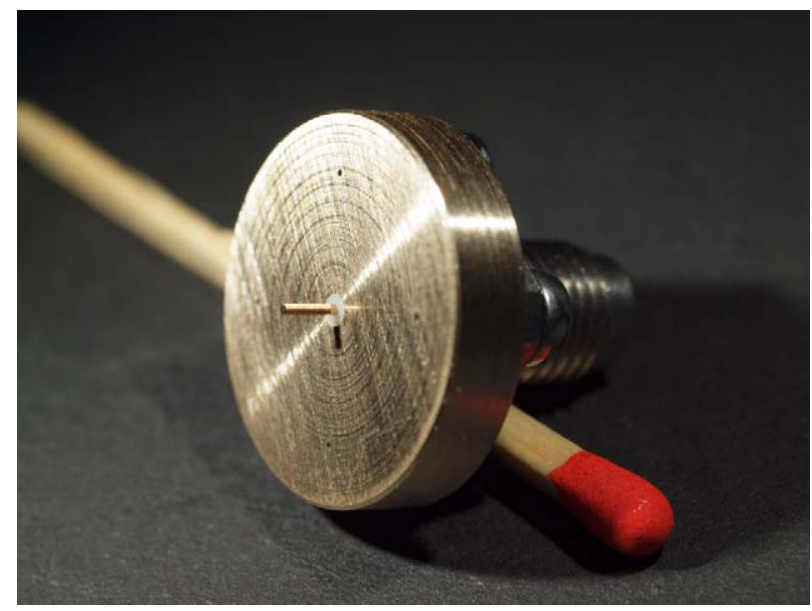

Figure 3 Ground plane with connector pin extension, Teflon washer and $1.85 \mathrm{~mm}$ connector on the back. [Color figure can be viewed in the online issue, which is available at wileyonlinelibrary.com]

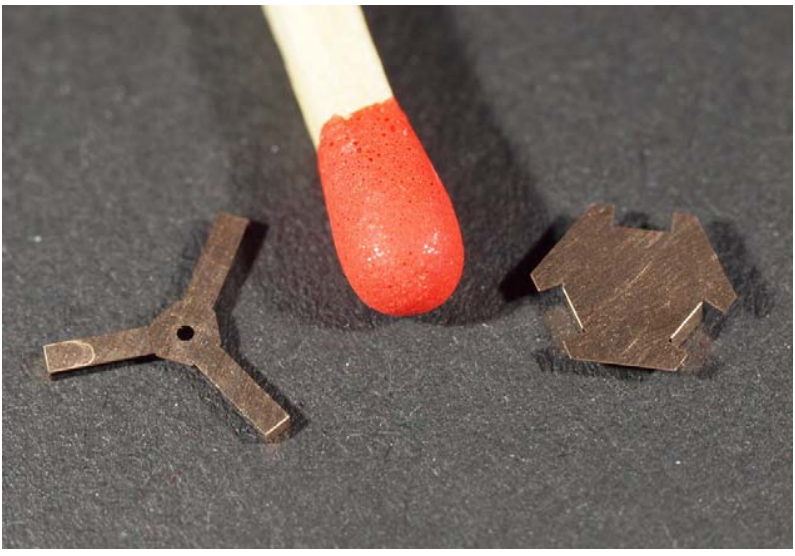

Figure 4 The antenna parts after etching and bending. [Color figure can be viewed in the online issue, which is available at wileyonlinelibrary.com]

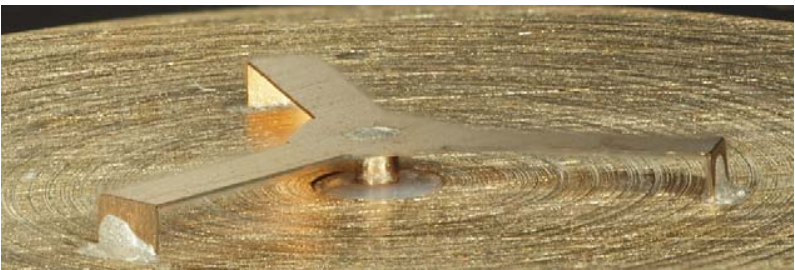

Figure 5 The antenna's first stage glued in place using silver epoxy. [Color figure can be viewed in the online issue, which is available at wileyonlinelibrary.com]

stage mounted on the GP and glued with silver epoxy; the pin extension of the connector has been shortened to the proper height and similarly glued to the first stage.

Then, the second stage of the antenna has been added using the same technique, and the complete antenna is visible in Figure 6; again a reference match is used to provide a scale estimation.

\section{4. $S_{11}$ MEASUREMENT AND COMPARISON WITH SIMULATION}

The antenna prototype was measured using an Agilent E8361A $(50 \mathrm{MHz}-67 \mathrm{GHz})$ ANA using electronic calibrator. Figure 7 shows a comparison of measured (-) and simulated (---) scattering parameters. The agreement between both frequency responses is good, with a measured BW somewhat wider than

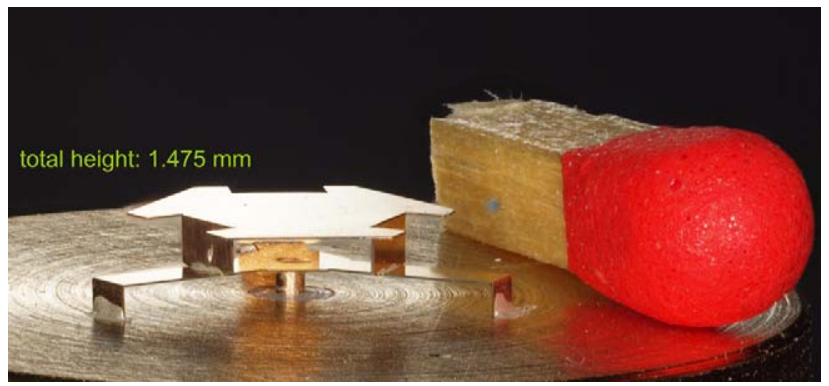

Figure 6 The TOLPA completely assembled, with indication of the height of the radiating part. [Color figure can be viewed in the online issue, which is available at wileyonlinelibrary.com] 


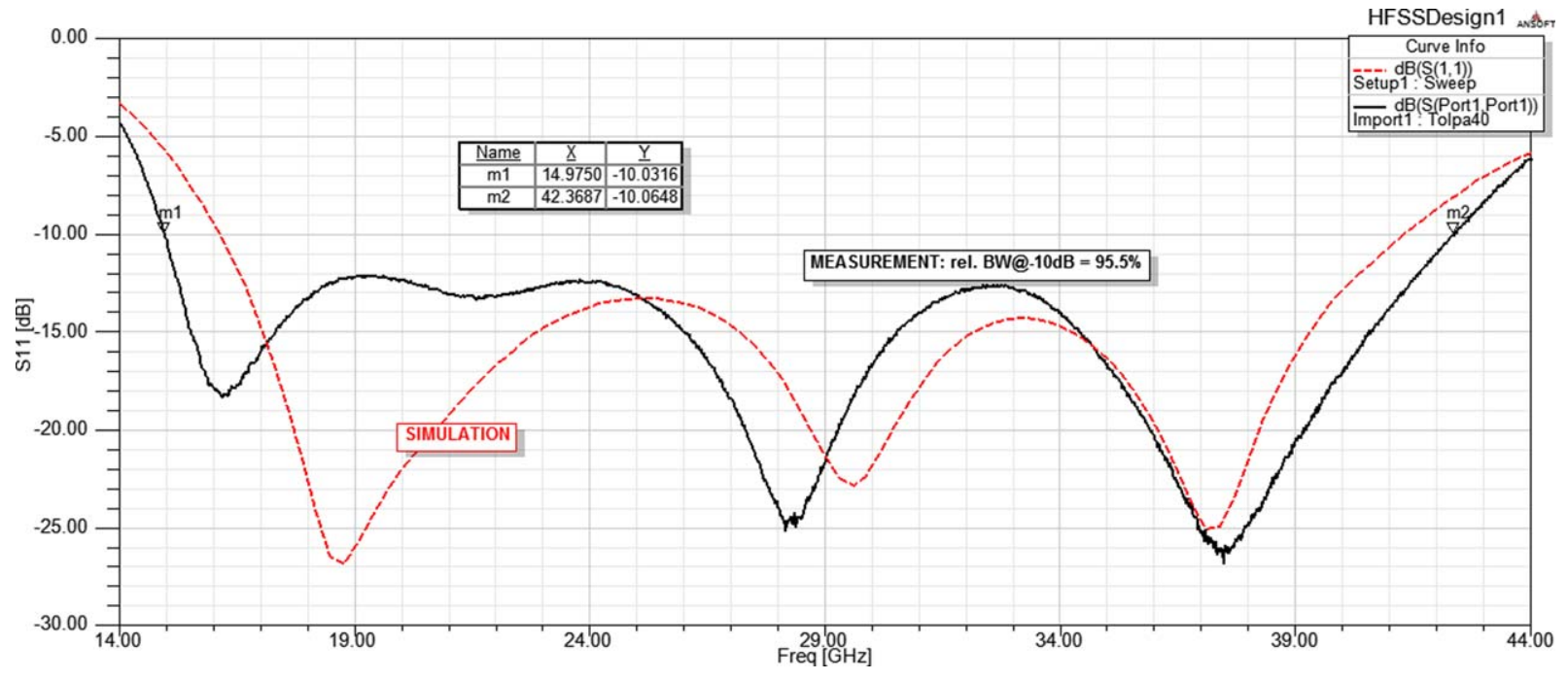

Figure 7 Measured (-) and simulated (---) $\mathrm{S}_{11}$. [Color figure can be viewed in the online issue, which is available at wileyonlinelibrary.com]

the simulated one. This might be due to ohmic losses, though these losses were already taken into account in the simulations and they should be quite low due to the fact that the antenna structure is entirely made of metallic good conductors. The measured BW (at $\mathrm{S}_{11}<-10 \mathrm{~dB}$ ) is $95.5 \%(14.97-42.37 \mathrm{GHz})$.

\section{ANTENNA RADIATION PATTERNS}

Of course radiation characteristics are of paramount importance for an antenna! Simulations have shown that across the full band where the antenna is matched the polarization remains vertical (E field perpendicular to the GP), with a quasiomnidirectional radiation pattern in the horizontal plane (in Fig. 1). In the vertical plane direction ( $z$ axis) there is a deep null for all frequencies, making the radiation pattern similar to that of a vertical monopole antenna. The maximum gain is practically in the horizontal plane at the low frequency edge; with increasing frequency, this maximum moves toward the vertical direction. In average, across the antenna operation band, the angle of maximum radiation keeps around $30^{\circ}$ in elevation.

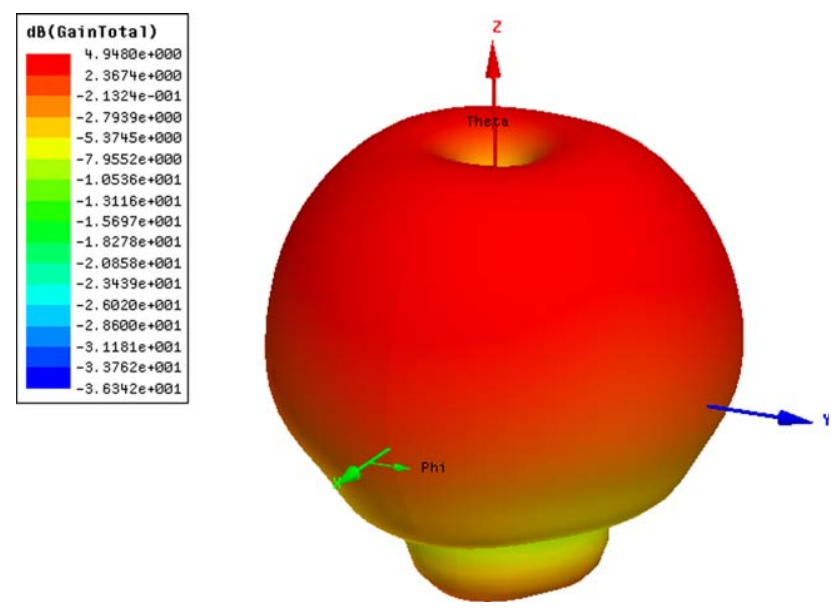

Figure 8 Simulated 3D radiation pattern at $28.5 \mathrm{GHz}$. [Color figure can be viewed in the online issue, which is available at wileyonlinelibrary.com]
Figure 8 shows the three dimensional (3D) simulated radiation pattern at $28.5 \mathrm{GHz}$. The maximum gain at this frequency is $+4.94 \mathrm{dBi}$. Table 1 shows the maximum simulated gain at five frequencies

Figure 9 shows the measured radiation patterns at five frequencies $(14.5,21.5,28.5,35.5$, and $42.5 \mathrm{GHz})$ in the $X Z$ plane (E-plane)

Figure 10 shows the measured radiation patterns at the same frequencies measured in the $X Y$ plane (H-plane) at $30^{\circ}$ above horizon $\left(\theta=60^{\circ}\right.$ in Fig. 9): this shows that the antenna is quasiomnidirectional, with a progressive degradation of this property with increasing frequency. The raw radiation patterns in the uppermost frequency point have been observed to be perturbed by an increased noise level. The origin of this noise is related with the performance degradation of the LNAs used in the measurement facility above $40 \mathrm{GHz}$, which reduces the signal to

TABLE 1 Maximum Simulated Gain as a Function of Frequency

\begin{tabular}{lc}
\hline $\mathrm{f}(\mathrm{GHz})$ & Maximum Simulated Gain $(\mathrm{dBi})$ \\
\hline 14.5 & +1.77 \\
21.5 & +3.72 \\
28.5 & +4.94 \\
35.5 & +6.04 \\
42.5 & +8.39 \\
\hline
\end{tabular}

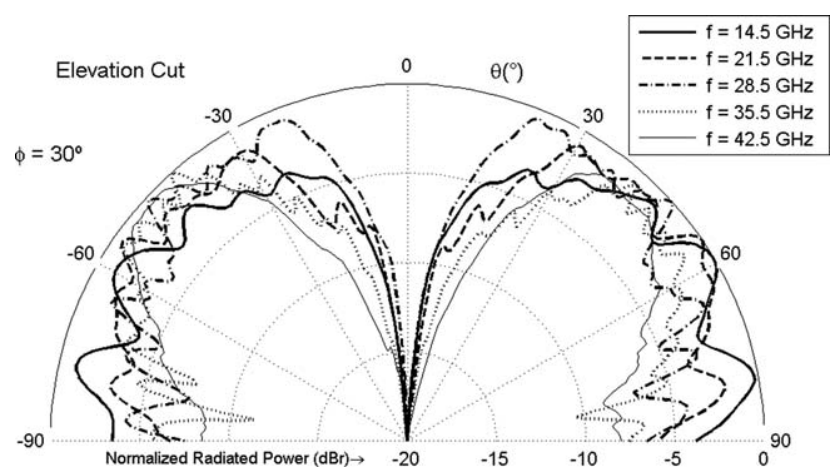

Figure 9 Measured E-plane radiation patterns for five frequencies 


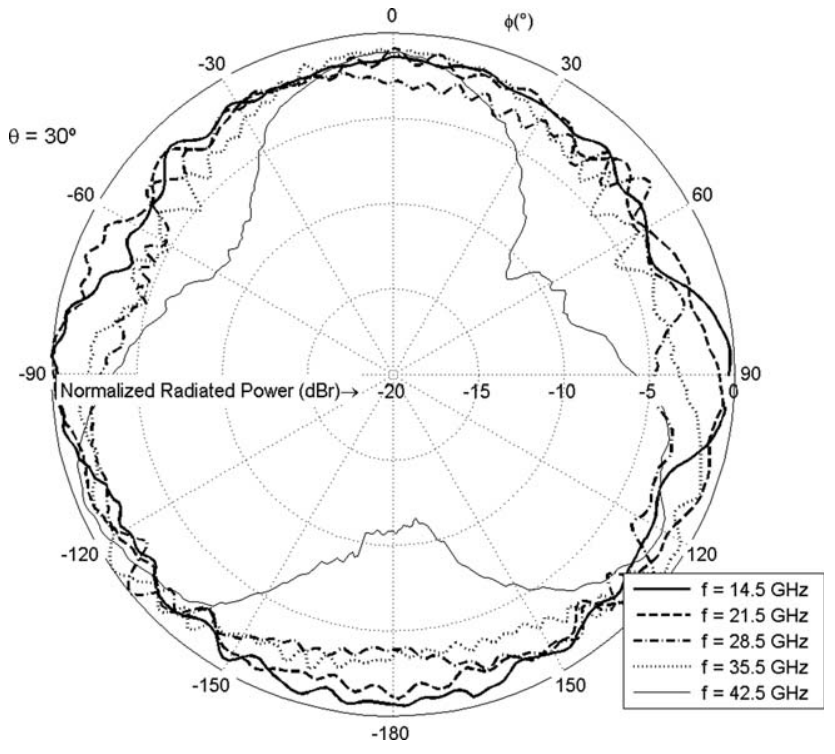

Figure 10 Measured H-plane radiation patterns at $30^{\circ}$ elevation for five frequencies

noise ratio of this measurement. For displaying purposes, the noise in the pattern measured at $42.5 \mathrm{GHz}$ has been filtered.

\section{CONCLUSIONS AND PERSPECTIVES}

The TOLPA concept presented in Ref. 2 has been shown to be easily adaptable to different frequency bands by rescaling its geometry. In this communication, a rescaling by a factor of four has been applied to cover the full $15-42 \mathrm{GHz}$ band with a vertically polarized quasi-omnidirectional radiation pattern. The proposed rescaling calls for special precautions in the antenna manufacturing, so as to guarantee the required quality of the realization. Through the entire $95.5 \%$ band the antenna preserves its radiation pattern, which resembles the one of a monopole on a ground plane.

Being made only of metallic parts, dielectric losses are avoided, the antenna adaptation to different frequency bands is made easier, and its manufacturing cost could be extremely low for large series realization. This antenna concept has numerous potential applications.

\section{ACKNOWLEDGMENTS}

The author is grateful to all people of ACI (Atelier de Circuits Imprimés) of the STI faculty of EPFL, for their help in producing the masks and fabricating the prototypes. A special thanks to Dr. Roberto Torres, who helped in producing some of the figures and reviewed the text of this paper.

\section{REFERENCES}

1. ANSYS HFSS, Available at: http://www.ansys.com/Products/Simulation + Technology/Electromagnetics/High-Performance +Electronic + Design/ANSYS + HFSS, Ansoft Corp., Pittsburgh, PA.

2. J.-F. Zürcher, TOLPA (tripod omnidirectional low profile antenna): A vertically polarized antenna with $90 \%$ bandwidth, Microwave Opt Technol Lett 55 (2013), 516-521.

(C) 2014 Wiley Periodicals, Inc.

\section{VERY BROADBAND PIFA ANTENNA FOR MOBILE COMMUNICATIONS AND ULTRAWIDEBAND SERVICES}

\author{
R. Gomez-Villanueva, ${ }^{1,2}$ R. Linares-y-Miranda, ${ }^{1}$ \\ J. A. Tirado-Mēndez, ${ }^{1}$ and $H$. Jardon-Aguilar ${ }^{2}$ \\ ${ }^{1}$ Seccion de Estudios de Posgrado e Investigacion, Escuela Superior \\ de Ingenieria Mecanica y Elēctrica (ESIME), Unidad Profesional \\ "Adolfo Lopez Mateos", Edif. 5, 3er piso, Col. Lindavista, C.P. \\ 07738, Mēxico D.F, Mēxico; Corresponding author: \\ rgomez@cinvestav.mx \\ ${ }^{2}$ Departamento de Ingenieria Elēctrica, Centro de Investigacion y de \\ Estudios Avanzados del Instituto Politēcnico Nacional (CINVESTAV). \\ Av. IPN 2508, Col. San Pedro Zacatenco, C.P. 07360, Mēxico D.F., \\ Mēxico
}

Received 7 May 2013

ABSTRACT: This article describes a very wideband planar inverted-F antenna antenna that covers the frequencies from 1.73 to $10.25 \mathrm{GHz}$ with $S 11<-10 \mathrm{~dB}$. This wideband encompasses the operating bands of mobile services such as DCS, PCS, LTE, WiMAX, WiFi, Bluetooth, and the major part of the ultrawideband spectrum. This new antenna has adequate radiation characteristics and dimensions of $4 \times 2 \times 1 \mathrm{~cm}^{3}$ that are suitable to be integrated in mobile terminals. (c) 2014 Wiley Periodicals, Inc. Microwave Opt Technol Lett 56:313-316, 2014; View this article online at wileyonlinelibrary.com. DOI 10.1002/mop.28049

Key words: antennas; mobile phone antennas; PIFA antennas; broadband antennas; ultrawideband antennas

\section{INTRODUCTION}

The accelerated advance in the mobile phone communications industry over the last years has created many technological options for the basic wireless voice and data communications. Therefore, we can currently find many radiofrequency standards (i. e., cellular, GSM, CDMA, LTE, WiFi, etc.) that operate in a wide variety of frequency bands ranging commonly between $800 \mathrm{MHz}$ and $6 \mathrm{GHz}$. These are the frequencies where the portable mobile communications are more feasible given the favorable propagation conditions. However, the ultrawideband services (UWB) devised as a suitable short-range and high-data rate transmission technology are extending the upper cut bandwidth of a wireless terminal to near of $10.6 \mathrm{GHz}$.

An antenna system capable of supporting all the services in all the bands referred earlier is not easy to accomplish. That is why the vast majority of the commercial terminals limit the number of bands in which they can work properly. For example, nowadays the most basic mobile phone is covering at least four bands in the cellular (800-900 MHz) and PCS-DCS (1800-1900 $\mathrm{MHz}$ ) region. However, many additional services require an additional support of WiFi, UMTS, LTE, and other frequencies.

In this article, a new antenna that covers most of the frequencies for mobile phone communications as well as the UWB frequencies is proposed. This antenna is an enhancement of a very wideband planar inverted-F antenna (PIFA) that was recently reported in [1]. In contrast to other wideband PIFA antennas developed in the past, this new antenna has been developed not with the purpose of creating many separated resonances through methods such as addition of parasitic patches [2], resonators elements [3], introduction of slots in the ground plane [4-6], slots in the main radiating structure [7], the employment of stacked elements [8], or a combination of different techniques. The antenna proposed here has a single UWB obtained through a combination of the following methods: the 